\title{
"Candidatus comitans," a Bacterium Living in Coculture with Chondromyces crocatus (Myxobacteria)
}

\author{
CHRISTOPH A. JACOBI, ${ }^{\dagger} \dagger$ HANS REICHENBACH, ${ }^{2}$ BRIAN J. TINDALL, ${ }^{1}$ \\ AND ERKO STACKEBRANDT ${ }^{1 *}$ \\ DSM-German Collection of Microorganisms and Cell Cultures, ${ }^{1}$ and GBF-Gesellschaft \\ für Biotechnologische Forschung, Abteilung Naturstoffbiologie, ${ }^{2}$ \\ D-38124 Braunschweig, Germany
}

\begin{abstract}
We describe the phylogenetic position and some taxonomically relevant characteristics of a small pleomorphic gram-negative bacterium that was cocultured with some strains of the myxobacterium Chondromyces crocatus that were isolated from the same geographic and ecological habitat. A $16 \mathrm{~S}$ ribosomal DNA analysis revealed that the companion was a member of the "Cytophaga-Flavobacterium-Bacteroides" complex and was most closely related to members of the genus Sphingobacterium. The results of a fatty acid analysis, an isoprenoid composition analysis, and a DNA G+C content analysis and the presence of sphingolipids confirmed that this bacterium is affiliated with the genus Sphingobacterium. As the companion bacterium survived for only a few generations on solid media and could not be maintained in pure culture, we assign to this novel taxon that lives in close association with the myxobacterium $C$. crocatus Candidatus status as "Candidatus comitans."
\end{abstract}

The myxobacteria are a phylogenetically coherent group of gram-negative, rod-shaped, gliding bacteria $(9,22)$ that have morphogenetically complex life cycles (19). Together with the gram-negative sulfur-reducing bacteria and the bdellovibrios, these organisms belong to the delta subclass of the Proteobacteria phylogenetically (28).

The presence of bacteria associated with the myxobacterium Chondromyces crocatus was reported as early as $1963(11)$. This myxobacterium is used to produce certain secondary metabolites $(7,8,20)$. The accompanying flora can be recognized a few hours after the start of fermentation and is present for several days before it disappears without being totally eliminated. Attempts to eliminate the companion organisms from $C$. crocatus cultures by separating the two bacteria on culture plates have been successful but have led to the death of the myxobacterium (11). The presence of uncharacterized contamination during the production of a chemical compound is unwanted and raises questions about the relationship between the organisms present in the bacterial association. In order to investigate whether a single bacterium or several species, referred to as companion(s) below, are associated with C. crocatus and to determine the taxonomic status of these bacteria, we analyzed the companions of several $C$. crocatus strains by molecular and chemotaxonomic methods.

\section{MATERIALS AND METHODS}

Bacterial strains. $C$. crocatus $\mathrm{Cm} \mathrm{c2,} \mathrm{Cm} \mathrm{c3}$, and $\mathrm{Cm} \mathrm{c4}$ were isolated from a soil sample collected in 1982 on Madeira. The host cell-companion cell associations have been deposited in the culture collection of $\mathrm{H}$. Reichenbach, GBFGesellschaft für Biotechnologische Forschung, Braunschweig, Germany. The companion strains of $C$. crocatus $\mathrm{Cm} \mathrm{c} 2, \mathrm{Cm} \mathrm{c} 3$, and $\mathrm{Cm} 44$ are strains $\mathrm{CJ} 2, \mathrm{CJ} 3$, and $\mathrm{CJ} 4$, respectively.

Culture conditions. $C$. crocatus was routinely grown in Pol 1 broth (7) at $30^{\circ} \mathrm{C}$

* Corresponding author. Mailing address: DSM-German Collection of Microorganisms and Cell Cultures, Mascheroder Weg 1B, D-38124 Braunschweig, Germany. Phone: 495312616 352. Fax: 495312616 418. Electronic mail address: erko@gbf-braunschweig.de.

$\dagger$ Present address: Institut für Hygiene und Mikrobiologie, 97080 Würzburg, Germany. in a shaking Erlenmeyer flask. The companion cells were cultivated on nutrient broth (NB) agar (Oxoid).

Morphological tests. The sizes and shapes of cells were determined by phasecontrast microscopy. The motility of cells was determined by growing the cells on soft agar.

Extraction and PCR amplification of $16 \mathrm{~S}$ rDNA. The cells in 1-ml portions of liquid $C$. crocatus cocultures were mechanically homogenized with glass beads (diameter 0.08 to $0.25 \mathrm{~mm}$; Roth, Karlsruhe, Germany) by vortexing. The beads were collected by centrifugation, and the cells were lysed enzymatically as described previously (17). Extraction of genomic DNA, amplification of $16 \mathrm{~S}$ ribosomal DNA (rDNA) by PCR, and purification of the PCR products were performed as described previously $(17,18)$.

Cloning of 16S rDNA amplification products. $16 \mathrm{~S}$ rDNA amplification products were cloned into plasmid vector pCRII (TA cloning system; Invitrogen, San Diego, Calif.) by using the method described in the manufacturer's instructions. Ligation products were transformed into competent cells supplied in the TA cloning kit. Clones were resuspended in sterile water and boiled for $10 \mathrm{~min}$. The preparation was centrifuged, and the supernatant was used to screen for $16 \mathrm{~S}$ rDNA insertions by PCR by using a conserved 16S rDNA primer pair (17).

Sequencing of insertions and phylogenetic analysis. Insertions were amplified by PCR, cleaned (17), and sequenced with a DyeDeoxy terminator sequencing kit (Applied Biosystems, Foster City, Calif.). The extension products were purified by treatment with phenol-chloroform, and a model 373A automated sequencer (Applied Biosystems) was used to separate the sequence products. The sequences were aligned manually with homologous $16 \mathrm{~S}$ rDNA sequences obtained from the Ribosomal Database Project (10). Pairwise evolutionary distances were computed by using the correction of Jukes and Cantor (6). Phylogenetic analyses were performed by using the algorithm of DeSoete (2) and the neighbor-joining method of Saitou and Nei (21). Initially, the sequences of the clones were compared with the sequences of representatives of the main lines of descent. Following identification of the phylum with which the clones clustered, a thorough phylogenetic analysis was performed with members of this phylum. Generation of companion cell mass. Cell mass was obtained by using a model TI 100 membrane fermentor (INFORS AG Einsbach, Germany). In principle, two cultures that were separated by a membrane that had defined a pore size $(40$ $\mathrm{kDa}$ ) were fermented. Substances, such as proteins, could pass through the membrane by free diffusion and thus could be used by the organisms (5).

Analysis of peptidoglycan. The cell wall was examined for the presence of meso-diaminopimelic acid by using whole-cell hydrolysates as described previously (18).

Extraction and analysis of lipoquinones, polar lipids, and sphingolipids. $\mathrm{Li}$ poquinones, polar lipids, and sphingolipids were extracted from $100 \mathrm{mg}$ of freeze-dried material by the two-stage method described previously $(26,27)$. The respiratory lipoquinones were separated into their different classes (menaquinones and ubiquinones) by thin-layer chromatography on silica gel thin layers (catalog no. 805023; Macherey-Nagel) by using hexane-ter-butylmethyl ether as the solvent. UV-absorbing bands corresponding to menaquinones or ubiquinones were removed from the plate and analyzed by high-performance liquid chromatography (HPLC). The HPLC analysis was performed with a model LDC analytical HPLC (Thermoseparations) equipped with a reverse-phase $3 \mu \mathrm{m}$ 


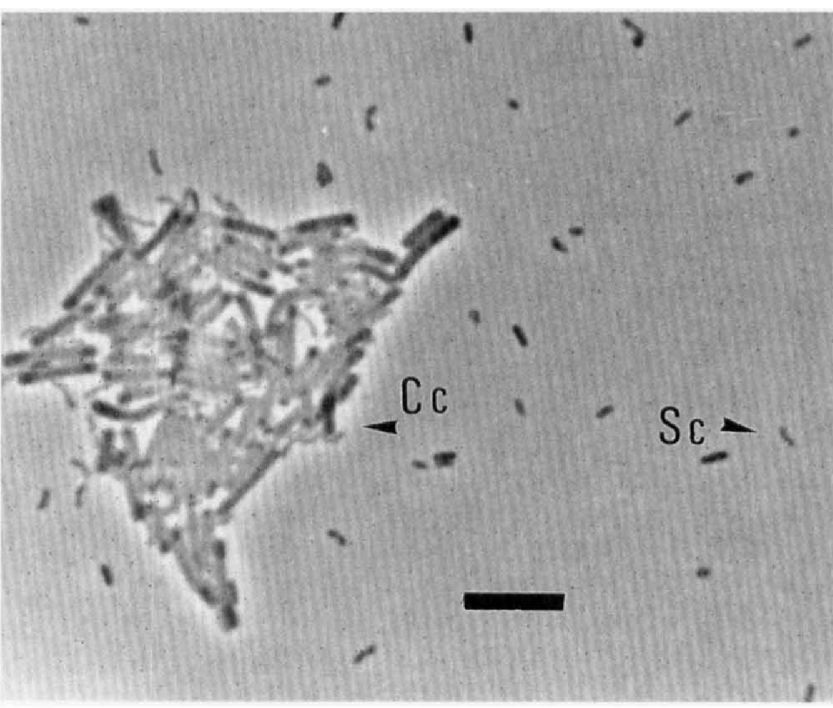

FIG. 1. Phase-contrast micrograph of cells of $C$. crocatus $\mathrm{Cm} \mathrm{c} 3(\mathrm{Cc})$ and companion strain $\mathrm{CJ} 3(\mathrm{Sc})$. Bar $=5 \mu \mathrm{m}$.

RP18 column ( 2 by $125 \mathrm{~mm}$; Macherey-Nagel); methanol was used as the eluant, and the respiratory lipoquinones were detected at $269 \mathrm{~nm}$.

The polar lipids were separated by two-dimensional silica gel thin-layer chromatography (catalog no. 818135; Macherey-Nagel); the gel was developed with chloroform-methanol-water $(65: 25: 4, \mathrm{vol} / \mathrm{vol} / \mathrm{vol})$ in the first dimension and with chloroform-methanol-acetic acid-water $(80: 12: 15: 4, \mathrm{vol} / \mathrm{vol} / \mathrm{vol} / \mathrm{vol})$ in the second dimension. The total lipids and specific functional groups were detected by using dodecmolybdophosphoric acid (total lipids), Zinzadze reagent (phosphate), ninhydrin (free amino groups), periodate-Schiff reagent ( $\alpha$-glycols), Dragendorff reagent (quaternary nitrogen), and anisaldehyde-sulfuric acid and alpha-naphthol-sulfuric acid (glycolipids)

The sphingolipids (as their free bases) were obtained by acid hydrolysis with 4 $\mathrm{M} \mathrm{HCl}-$ methanol $(1: 1, \mathrm{vol} / \mathrm{vol})$ at $100^{\circ} \mathrm{C}$ for $3 \mathrm{~h}$. After the solution was made alkaline with $\mathrm{NaOH}$, the free bases were extracted with tert-butylmethyl ether. The N,O-bis(trimethylsilyl)acetamide derivatives were analyzed by gas chromatography by using the conditions described above.

Extraction and analysis of fatty acids. Fatty acid methyl esters were obtained from freeze-dried biomass by sonification, methylation, and extraction by the method of Miller (13). The fatty acid methyl ester mixtures were separated by using a model 5898A microbial identification system (Microbial ID, Inc., Newark, Del.) (12). The following conditions were used: injection and detector port temperature, $300^{\circ} \mathrm{C}$; inlet pressure, $80 \mathrm{kPa}$; split ratio, $50: 1$; injection volume, 1 $\mu \mathrm{l}$; and a temperature program in which the temperature increased from 130 to $310^{\circ} \mathrm{C}$ at a rate of $4^{\circ} \mathrm{C} / \mathrm{min}$.

Determination of the DNA $\mathrm{G}+\mathrm{C}$ content. The methods used to determine the $\mathrm{G}+\mathrm{C}$ content have been described previously $(12,25)$. Approximately $20 \mu \mathrm{g}$ of DNA was hydrolyzed and dephosphorylated, and the nucleosides were separated by reverse-phase HPLC. The retention times of the nucleosides were determined with synthetic compounds. Nonmethylated lambda phage DNA having a $\mathrm{G}+\mathrm{C}$ content of $49.858 \mathrm{~mol} \%$ (16) was used as the calibration reference.

Nucleotide sequence accession numbers. The $16 \mathrm{~S}$ rDNA nucleotide sequence which we determined has been deposited in the EMBL database under accession number X91814.

\section{RESULTS}

Morphology. Microscopic investigations of $C$. crocatus broth cultures revealed that some cultures of this myxobacterium contained two different cell types; in addition to the characteristic $C$. crocatus cells, small, slender, pleomorphic cells were observed (Fig. 1). Inoculation of NB agar with contaminated C. crocatus liquid cultures resulted in the appearance of very small, convex, opaque colonies of different sizes after 7 days. The edges of these colonies were smooth and round (Fig. 2). The cell mass appeared to be orange after fermentation cultures were concentrated. An examination of the companion cells obtained from pure cultures on NB agar and from the cocultures revealed two different cell morphologies; while the

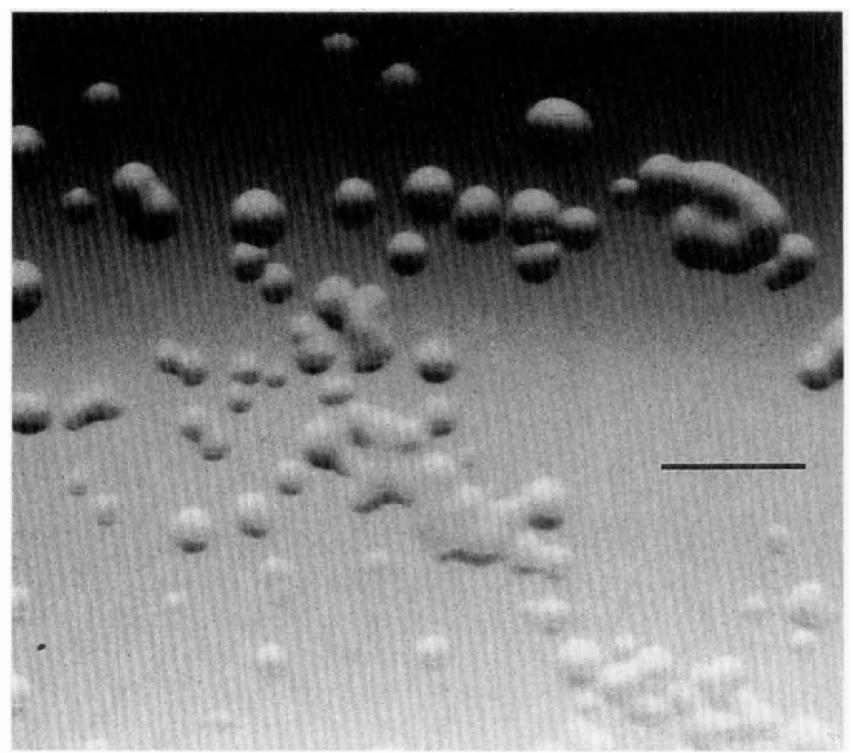

FIG. 2. Size and morphology of companion strain CJ3 colonies. Bar $=1$ $\mathrm{mm}$.

pure cultures contained highly pleomorphic, spheroplast-like cells that were 2.0 to $4.0 \mu \mathrm{m}$ long and up to $1.0 \mu \mathrm{m}$ in diameter (Fig. 3 ), the cells in cocultures with $C$. crocatus were small, slender, only slightly pleomorphic, gram-negative rods that were 1.0 to $2.0 \mu \mathrm{m}$ long and about $0.5 \mu \mathrm{m}$ in diameter (Fig. 1). The highly pleomorphic cells of the pure cultures turned into slightly pleomorphic cells when they were cocultivated with pure cultures of other strains of $C$. crocatus (5). In pure cultures, cells of the companion organism grew aerobically at

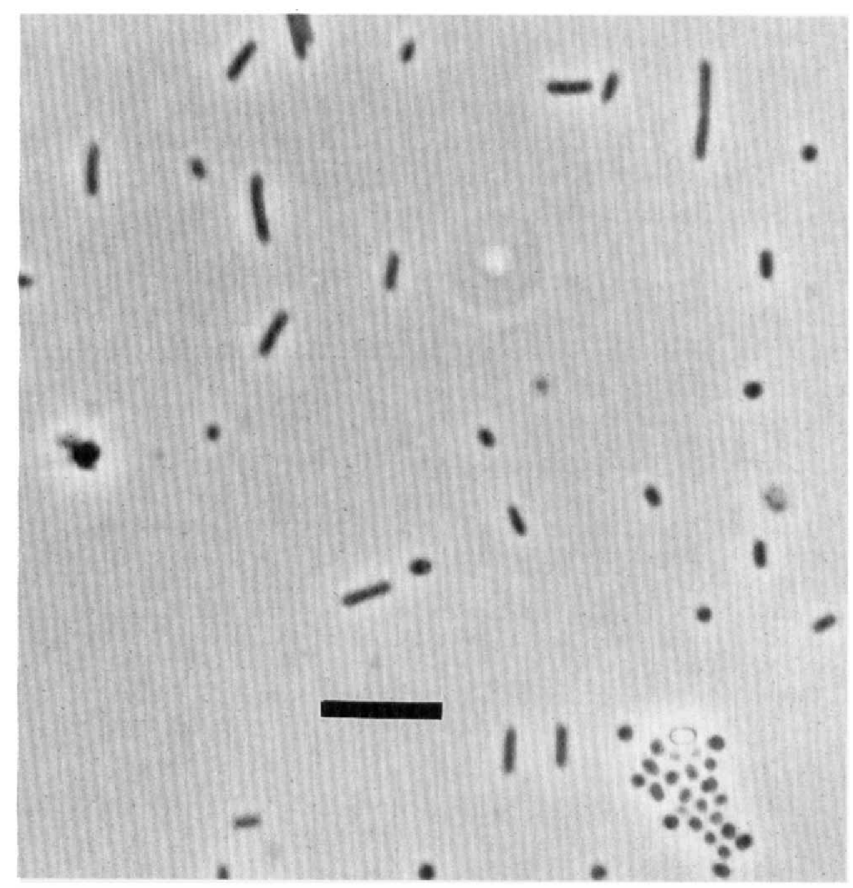

FIG. 3. Phase-contrast micrograph of a pure culture of companion strain $\mathrm{CJ} 3$, showing the rod-shaped, pleomorphic, and degenerate cell morphologies. Bar $=5 \mu \mathrm{m}$. 
TABLE 1. 16S rDNA dissimilarity values for isolate CJ3 and the type strains of species belonging to the genera Sphingobacterium, Flexibacter, Cytophaga, Empedobacter, and Chryseobacterium ${ }^{a}$

\begin{tabular}{|c|c|c|c|c|c|c|c|c|c|}
\hline \multirow[b]{2}{*}{ Organism } & \multicolumn{9}{|c|}{$\% 16 \mathrm{~S}$ rDNA dissimilarity } \\
\hline & $\begin{array}{l}\Omega \\
己 \\
\stackrel{0}{0} \\
\stackrel{0}{0}\end{array}$ & 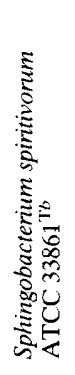 & 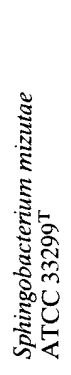 & 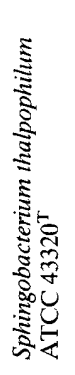 & 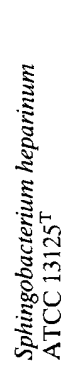 & 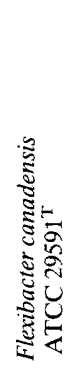 & 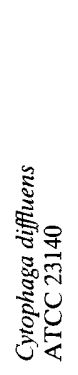 & 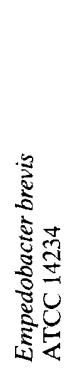 & 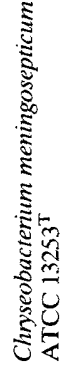 \\
\hline Sphingobacterium spiritivonum ATCC $33861^{\mathrm{T}}$ & 9.4 & & & & & & & & \\
\hline Sphingobacterium mizutae ATCC $33299^{\mathrm{T}}$ & 9.4 & 6.9 & & & & & & & \\
\hline Sphingobacterium thalpophilum ATCC $43320^{\mathrm{T}}$ & 10.1 & 7.4 & 6.7 & & & & & & \\
\hline Cytophaga diffluens ATCC 23140 & 17.7 & 16.6 & 16.8 & 17.3 & 18.4 & 18.2 & & & \\
\hline Empedobacter brevis ATCC 14234 & 18.7 & 19.5 & 20.4 & 19.4 & 19.2 & 18.5 & 19.2 & & \\
\hline Chryseobacterium meningosepticum ATCC $13253^{\mathrm{T}}$ & 19.6 & 18.2 & 19.1 & 18.3 & 20.1 & 16.6 & 17.5 & 9.0 & \\
\hline Chryseobacterium indologenes ATCC $29897^{\mathrm{T}}$ & 23.0 & 21.5 & 21.9 & 21.0 & 23.2 & 20.5 & 19.9 & 12.4 & 6.1 \\
\hline
\end{tabular}

${ }^{a}$ Data from reference 10.

${ }^{b} \mathrm{~T}=$ type strain.

temperatures between 20 and $30^{\circ} \mathrm{C}$ but not at $37^{\circ} \mathrm{C}$. No growth occurred under microaerophilic or anaerobic conditions.

Phylogenetic analyses. We determined an almost complete 16S rDNA sequence (length, 1,486 bases) for companion strain $\mathrm{CJ} 2$ of $C$. crocatus $\mathrm{Cm} \mathrm{c} 2$ and about 800 nucleotides of the sequences of companion strains $\mathrm{CJ} 3$ and $\mathrm{CJ} 4$ of $C$. crocatus $\mathrm{Cm}$ $\mathrm{c} 3$ and $\mathrm{Cm} \mathrm{c4}$, respectively. The levels of similarity were virtually identical $(>99.8 \%)$ for the common region analyzed in the three companion strains. The sequence of CJ2 was also compared with the homologous sequences of a broad range of prokaryotic taxa. The closest phylogenetic relatives were members of the "sphingobacter" subgroup of the "Cytophaga-Falvobacterium-Bacteroides" phylum (3). Strain CJ2 exhibited the highest levels of $16 \mathrm{~S}$ rDNA similarity (more than $90 \%$ similarity) with strains belonging to the genus Sphingobacterium (Table 1 shows the dissimilarity values used to generate the distance matrix tree) and related taxa. The $\mathrm{CJ} 2$ sequence had all of the signature nucleotides identified for the "sphingobacter" subgroup (3). The relationships of strain CJ2 with the phylogenetically most closely related species for which sequence data are available are shown in Fig. 4.

Chemotaxonomic properties of strain $\mathbf{C J 3}$. Our cell wall analyses confirmed that strain $\mathrm{CJ} 3$ contained meso-diaminopimelic acid, which is the diagnostic amino acid of gramnegative cell walls.

Menaquinone MK-7 was the major isoprenoid quinone ( $99 \%$ of the total isoprenoid quinones). With the exception of phosphatidylethanolamine, all of the strain CJ3 polar lipids, which differed from the polar lipids of $C$. crocatus $\mathrm{Cm}$ c2, could not be identified as known lipids (data not shown). Fatty acids iso- $\mathrm{C}_{15: 0}\left(33 \%\right.$ of the total fatty acids) and iso-2-OH-C $\mathrm{C}_{15: 0}$ $(31 \%)$ dominated the fatty acid pattern of strain $\mathrm{CJ} 3$, while straight-chain fatty acids $\left(\mathrm{C}_{15: 0}\right.$ and $\mathrm{C}_{16: 0}[7$ and $3 \%$, respectively] and iso-3-OH- $\mathrm{C}_{17: 0}(8 \%)$ occurred in smaller amounts. Unknown sphingolipids were also present. More detailed information could not be obtained because of the small amount of cell mass available. It should be noted that the cells used to determine chemotaxonomic properties were not grown under strictly standardized conditions, as cell mass was harvested from a bioreactor after different lengths of time ( 3 to 5 days). The $\mathrm{G}+\mathrm{C}$ content of the strain CJ3 DNA was $35.9 \mathrm{~mol} \%$.

Physiological properties. Physiological and biochemical characteristics could not be determined by the API system (bio-Merieux Vitek, Marcy-l'Etoile, France), by the Biolog system (Biolog, Inc., Hayward, Calif.), or in any other medium suitable for the cultivation of sphingobacteria as growth of the companion organisms was not supported.

\section{DISCUSSION}

Our phylogenetic analysis showed that companion strains $\mathrm{CJ} 2, \mathrm{CJ} 3$, and CJ4 were related to the genus Sphingobacterium. This genus can be distinguished phenotypically from its phylogenetic neighbors (e.g., saprospiras, cytophagas, and flavobacteria) by the presence of sphingolipids $(4,23,24,29)$, a

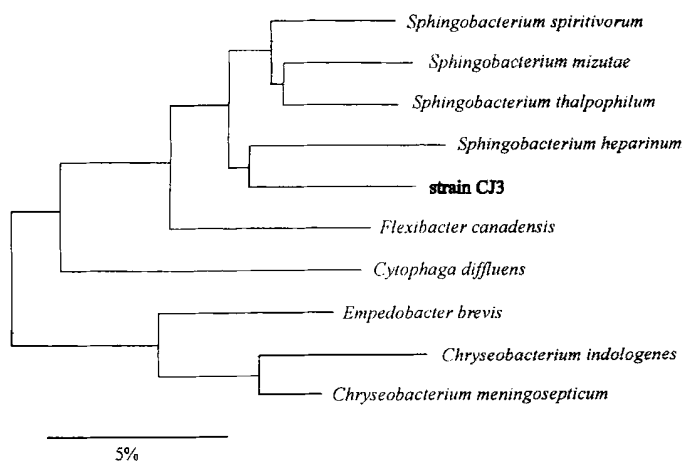

FIG. 4. Phylogenetic tree showing the positions of isolate CJ3 (designated "Candidatus comitans" in this study), members of the genus Sphingobacterium, and representatives of related genera, based on $16 \mathrm{~S}$ rDNA sequence comparisons. $\mathrm{Bar}=0.05$ estimated nucleotide change per position. 
substance also found in strain CJ3. The cell morphology, Gram staining behavior, and color of the cell mass were consistent with the genus description, as was the presence of iso2-OH- $\mathrm{C}_{15: 0}$ as a major fatty acid (29) and the predominance of menaquinone MK-7 (1). Unfortunately, some genus-specific characteristics, such as resistance to certain antimicrobial agents, oxidation of carbohydrates, lack of indole production, and proteolytic activity, could not be studied because the companion strains did not grow on the appropriate media.

The phylogenetic position of strain $\mathrm{CJ} 2$ is within the radiation of the four Sphingobacterium species that have been studied; this strain occurs with Sphingobacterium heparinum on a separate line of descent. The gliding, flexible, thin, rod-shaped organism Flexibacter canadensis appears to be the closest nonSphingobacterium relative of strain CJ2. As only one-half of the Sphingobacterium species that have been described have been subjected to $16 \mathrm{~S}$ rDNA analysis so far, we could not determine whether strain CJ3 is more closely related to another Sphingobacterium species than to $S$. heparinum. Furthermore, because of our the inability to obtain sufficient cell material for DNA isolation, nucleic acid hybridization studies could not be performed with any of the Sphingobacterium type strains that have been described.

Despite the presence of Sphingobacterium-specific characteristics in strains $\mathrm{CJ} 2, \mathrm{CJ} 3$, and $\mathrm{CJ} 4$ and the unique ecological niche of these organisms as companions of $C$. crocatus, as well as their inability to survive without the host cells and the limited information concerning the proper taxonomic affiliation, it would not be wise to describe the companion bacterium as a new Sphingobacterium species. On the other hand, there is sufficient information to place the companion organism in a provisional Candidatus taxon, which is used to describe to record the properties of a putative taxon of prokaryotes (14, 15 ). The authenticity of the companion organism located in the sporangioles of $C$. crocatus has been verified by in situ hybridization with a fluorescently labelled $16 \mathrm{~S}$ rDNA oligonucleotide (5).

"Candidatus comitans" [(Bacteroides-Cytophaga-Flavobacterium phylum, related to members of the genus Sphingobacterium); $\mathrm{C}$, for a few generations on solid media; $\mathrm{G}-; \mathrm{R}$, nonmotile; NAS (EMBL accession number 91814), oligonucleotide sequence complementary to unique region of 16S rRNA 5'-CTCAAAGAAAGCAAGCTCTCC-3'; S (Chondromyces crocatus, sporangioles); aer., sphingolipids + , phosphatidylethanolamine + , iso- $\mathrm{C}_{15: 0}$ and iso-2-OH- $\mathrm{C}_{15: 0}$ fatty acids + , respiratory quinone MK-7, G+C content of the DNA $36 \mathrm{~mol} \%$.

\section{ACKNOWLEDGMENTS}

We thank F. A. Rainey for operating the automatic sequencer, R. M. Kroppenstedt for determining the fatty acid composition, N. Weiss for determining the cell wall composition, Infors GmbH for letting us use a fermentation device, and B. Kunze for providing strains and information concerning culture conditions.

\section{REFERENCES}

1. Dees, S. B., G. M. C. Hollis, and C. W. Moss. 1985. Chemical and phenotypic characteristics of Flavobacterium thalpophilum compared with those of other Flavobacterium and Sphingobacterium species. Int. J. Syst. Bacteriol. 35: 16-22.

2. DeSoete, G. 1983. A least square algorithm for fitting additive trees to proximity data. Psychrometrika 48:621-626.

3. Gherna, R., and C. R. Woese. 1992. A partial phylogenetic analysis of the "Flavobacter-Bacteroides" phylum: basis for taxonomic restructuring. Syst. Appl. Microbiol. 15:513-521.

4. Holmes, B., J. Owen, and A. McMeekin. 1984. Genus Flavobacterium Bergey, Harrison, Breed, Hammer and Huntoon 1923,97, p. 353-361. In N. R. Krieg, and J. G. Holt (ed.), Bergey's manual of systematic bacteriology, vol. 1. The Williams and Wilkins Co., Baltimore.

5. Jacobi, C. A., B. Assmus, H. Reichenbach, and E. Stackebrandt. Unpublished data.

6. Jukes, T. H., and C. R. Cantor. 1969. Evolution of protein molecules, p. 21-132. In H. N. Munro (ed.), Mammalian protein metabolism. Academic Press, New York.

7. Kunze, B., R. Jansen, G. Höfle, and H. Reichenbach. 1994. Crocacin, a new electron transport inhibitor from C. crocatus (myxobacteria). Production, isolation and physico-chemical and biological properties. J. Antibiot. 47:881886

8. Kunze, B., R. Jansen, F. Sasse, G. Höfle, and H. Reichenbach. Chondramides A-D, new antifungal and cytostatic depsipeptides from Chondromyces crocatus (myxobacteria). Production, physico-chemical and biological properties. J. Antibiot., in press.

9. Ludwig, W., K. H. Schleifer, H. Reichenbach, and E. Stackebrandt. 1983. A phylogenetic analysis of the myxobacteria Myxococcus fulvus, Stigmatella aurantiaca, Cystobacter fuscus, Sorangium cellulosum and Nannocystis exedens. Arch. Microbiol. 135:58-62.

10. Maidak, B. L., N. Larsen, M. A. McCaughey, R. Overbeek, G. J. Olsen, K. Fogel, J. Blandy, and C. R. Woese. 1994. The Ribosomal Database Project. Nucleic Acids Res. 22:3485-3487.

11. McCurdy, H. D. 1963. A method for the isolation of myxobacteria in pure culture. Can. J. Microbiol. 16:1453-1461.

12. Mesbash, M., U. Premachandran, and W. Whitman. 1989. Precise measurement of the $\mathrm{G}+\mathrm{C}$ content of deoxyribonucleic acid by high-performance liquid chromatography. Int. J. Syst. Bacteriol. 39:159-167.

13. Miller, L. T. 1982 . A single derivatization method for bacterial fatty acid methyl esters including hydroxy acids. J. Clin. Microbiol. 16:584-586.

14. Murray, R. G. E., and K.-H. Schleifer. 1994. Taxonomic notes: a proposal for recording the properties of putative taxa of prokaryotes. Int. J. Syst. Bacteriol. 44:174-176.

15. Murray, R. G. E., and E. Stackebrandt. 1995. Taxonomic note: implementation of the provisional status Candidatus for incompletely described procaryotes. Int. J. Syst. Bacteriol. 45:186-187.

16. Normore, W. M. 1976. Guanine-plus-cytosine (GC) composition of the DNA of bacteria, fungi, algae, and protozoa, p. 65-232. In G. D. Fasman (ed.) $\mathrm{CRC}$ handbook of biochemistry and molecular biology, $3 \mathrm{rd}$ ed., vol. II. CRC Press, Cleveland.

17. Rainey, F. A., M. Dorsch, H. W. Morgan, and E. Stackebrandt. 1992. 16 S rDNA analysis of Spirochaeta thermophila: its phylogenetic position and implications for the systematics of the order Spirochaetales. Syst. Appl. Microbiol. 15:197-202.

18. Rainey, F. A., N. Weiss, and E. Stackebrandt. 1995. Phylogenetic analysis of the genera Cellulomonas, Promicromonospora, and Jonesia and proposal to exclude the genus Jonesia from the family Cellulomonadaceae. Int. J. Syst. Bacteriol. 45:649-652

19. Reichenbach, H. 1993. Biology of the myxobacteria: ecology and taxonomy, p. 13-62. In M. Dworkin and D. Kaiser. (ed.), Myxobacteria II. American Society for Microbiology, Washington, D.C.

20. Reichenbach, H., and G. Höfle. 1993. Biologically active secondary metabolites from myxobacteria. Biotechnol. Adv. 11:219-277.

21. Saitou, N., and M. Nei. 1987. The neighbor-joining method: a new method for reconstructing phylogenetic trees. Mol. Biol. Evol. 4:406-425.

22. Shimkets, L., and C. R. Woese. 1992. A phylogenetic analysis of the myxobacteria: basis of their classification. Proc. Natl. Acad. Sci. USA 89:9459 9463.

23. Shivaji, S., M. K. Ray, N. S. Rao, L. Saisree, M. V. Jagannadham, G. S Kumar, G. S. N. Reddy, and P. M. Bhargava. 1992. Sphingobacterium antarcticus $\mathrm{sp}$. nov., a psychrotrophic bacterium from the soils of Schirmacher Oasis, Antarctica. Int. J. Syst. Bacteriol. 42:102-106.

24. Takeuchi, M., and A. Yokota. 1992. Proposal of Sphingobacterium faecium sp nov., Sphingobacterium piscium sp. nov., Sphingobacterium heparinum comb nov., Sphingobacterium thalpophilum comb. nov. and two genospecies of the genus Sphingobacterium and synonomy of Flavobacterium yabuuchiae and Sphingobacterium spiritivonum. J. Gen. Appl. Microbiol. 38:465-482

25. Tamaoka, J., and K. Komagata. 1984. Determination of DNA base composition by reverse-phase high performance liquid chromatography. FEMS Microbiol. Lett. 25:125-128.

26. Tindall, B. J. 1990. A comparative study of the lipid composition of Halobac terium saccharovonum from various sources. Syst. Appl. Microbiol. 13:128130 .

27. Tindall, B. J. 1990. Lipid composition of Halobacterium lacusprofundi. FEMS Microbiol. Lett. 66:199-202.

28. Woese, C. R. 1987. Bacterial evolution. Microbiol. Rev. 51:221-271.

29. Yabuuchi, E., T. Kaneko, I. Yano, C. W. Moss, and N. Miyoshi. 1983. Sphingobacterium gen. nov., Sphingobacterium spiritivorum comb. nov. Sphingobacterium multivorum comb. nov., Sphingobacterium mizutae sp. nov., and Flavobacterium indologenes sp. nov.: glucose-nonfermenting gram-negative rods in CDC groups IIK-2 and IIb. Int. J. Syst. Bacteriol. 33:580-598. 